\title{
ISOLAMENTO, FRACIONAMENTO E CARACTERIZAÇÃO DE PAREDES CELULARES DE RAÍZES DE MANDIOCA (Manihot esculenta, Crantz) ${ }^{1}$
}

\author{
Lara Tschopoko Pedroso PEREIRA², Adelaide del Pino BELÉIA ${ }^{3, *}$
}

\begin{abstract}
RESUMO
Durante a cocção de mandiocas o amido é gelatinizado e as paredes celulares sofrem alterações físicas e químicas que modificam a coesão das células e causam o amaciamento dos tecidos. Isolar, fracionar e caracterizar paredes celulares durante o envelhecimento de raizes, de duas cultivares, foram os objetivos deste trabalho. $\mathrm{O}$ amido foi eliminado por tamização e hidrólise enzimática e o material de paredes celulares foi fracionado em celulose, hemicelulose e pectina. Quantitativamente celulose foi a maior fração constituindo entre 57,2 e $70 \%$ do material inicial de paredes celulares isoladas, seguido por pectina e hemicelulose. O material isolado como paredes celulares diminuiu com o tempo de plantio das raizes e a concentração de celulose foi menor no material isolado de raízes mais velhas. A fração pectina diferiu em concentração de açúcares entre raízes de idades diferentes, sendo mais alta em raízes mais velhas enquanto a concentração de ácidos urônicos diferiu entre idades e cultivares.

Palavras-chave: paredes celulares; celulose; pectina; hemicelulose; mandioca (Manihot esculenta).
\end{abstract}

\section{SUMMARY}

ISOLATION, FRACTIONATION AND CHARACTERIZATION OF CASSAVA (Manihot esculenta, Crantz) ROOT CELL WALLS. During cooking of cassava tubers starch gelatinizes and there are physical-chemical alterations in cell wall material, reducing intercellular cohesion and softening the tissue, playing an important role in cooking time. Cell wall material from tubers at two harvesting ages of two cultivars were isolated, fractionated and evaluated. Starch was eliminated by wet sieving and enzymatic hydrolysis and the cell wall material was fractionated into cellulose, hemicellulose and pectin. Quantitatively cellulose had the highest concentration varying from 57.2 to $70 \%$ of the initial isolated cell wall material, followed by pectin and hemicellulose. Cell wall material isolated decreased with the age of the roots and cellulose concentration decreased in the older roots. Pectin fraction differed in sugar concentration between roots of different ages, higher in older roots while for uronic acid content there were differences for age of roots and cultivars.

Keywords: cell walls; cellulose; pectin; hemicellulose; cassava (Manihoc sculenta).

\section{1 - INTRODUÇÃO}

A mandioca é um dos vegetais mais cultivados no mundo, especialmente nos trópicos, sendo o Brasil um dos principais países produtores. As raízes tuberosas são usadas como matéria-prima industrial para a produção de polvilho doce e azedo e farinhas de vários tipos, mas são também consumidas após tratamento térmico. O consumo de raízes frescas já foi muito mais importante no hábito alimentar brasileiro, mas cereais consumidos em diferentes formulações alimentares ou como ingredientes de uma gama muito grande de produtos industrializados, têm substituído a mandioca por serem mais fáceis ou mais rápidos de preparar.

A textura final do produto cozido é a principal característica de qualidade exigida pelo consumidor de mandiocas [8, 15, 22]. Modificações durante a cocção que alteram a textura estão relacionadas com o amido, o principal componente do interior das células e com as paredes celulares, que definem o grau de coesão entre as células e as características do tecido. A célula vegetal é envolta pela plasmalema (membrana celular) e no exterior desta está a parede celular primária e a lamela média, estrutura que é composta por substân-

1. Recebido para publicação em 26/07/2002. Aceito para publicação em 01/12/2003 (000960).

2. Universidade Estadual de Ponta Grossa. E-mail: tschopoko@interponta. com.br

3. Universidade Estadual de Londrina, Depto. de Tecnologia de Alimentos e Medicamentos. E-mail: beleia@uel.br

*A quem a correspondência deve ser enviada. cias que cimentam as células entre si e que contém polissacarídeos, glicoproteínas e compostos fenólicos. Muito da textura de tecidos vegetais pode ser atribuído à integridade estrutural da parede celular, da lamela média e da turgescência de líquidos ou grânulos de amido crus ou gelatinizados. A lamela média é lábil sob ação do calor de cocção e após a solubilização da pectina as células vegetais separam-se facilmente, marcando o ponto final da cocção [14].

Constituintes de paredes celulares foram quantificados por CARVALHO, CHAGAS \& COSTA [5] que determinaram pectina, hemicelulose e celulose diretamente em tecidos de raízes de mandioca de 3 cultivares, colhidas 18 meses após o plantio. RAUPP et al. [21] determinaram fibra alimentar, composta principalmente por substâncias das paredes celulares, em amostras comerciais de farinhas obtidas de fecularias após a extração parcial de amido. SALVADOR et al. [23] determinaram a composição em monossacarídeos de polissacarídeos de paredes celulares isoladas de farinhas de mandioca. O objetivo deste trabalho foi isolar, fracionar e caracterizar material de parede celular de 2 cultivares de mandioca colhidos 7 e 19 meses após o plantio.

\section{2 - MATERIAL E MÉTODOS}

\section{1 - Matéria-prima}

A mandioca fresca foi colhida no sítio Mirantro, situado na zona rural do município de Londrina, PR, situado a $23^{\circ} 19^{\prime}$ de latitude sul, $51^{\circ} 12^{\prime}$ de longitude 
oeste e altitude média de $575 \mathrm{~m}$. Foram utilizados para análise da parede celular os cultivares IAPAR-19 Pioneira e Catarina Amarela, plantados em outubro de 1997 e outubro de 1998, em solo classificado como terra roxa estruturada eutrófica, sem adubação e colhidas e analisadas no mês de maio de 1999, aos 19 e 7 meses após o plantio. Geralmente aos 19 meses de plantio as raízes não são mais comercializadas, mas queríamos material que permitisse determinações de diferenças devido ao tempo de plantio. Estas cultivares são produzidas nesta região, em várias propriedades, e vendidas descascadas e embaladas para consumo doméstico.

\section{2 - Composição química das raízes descascadas e do resíduo}

Foram usados métodos da AMERICAN ASSOCIATION OF CEREAL CHEMISTS - AACC [1]: para umidade, lipídios, nitrogênio total (Micro Kjeldahl, utilizando o fator de conversão de 6,25) e cinzas. Fibra bruta, estimada como parte dos carboidratos resistentes aos tratamentos sucessivos com ácido e base diluídos, foi determinada conforme método descrito pela ASSOCIATION OF OFFICIAL ANALITICAL CHEMISTS - AOAC [3]. O teor de amido foi determinado conforme método quantitativo descrito nas Normas Analíticas do INSTITUTO ADOLFO LUTZ [9], após hidrólise ácida a glicose formada é quantificada pelo método titulométrico com reagente de Fehling.

\section{3 - Isolamento e fracionamento da parede celular}

Foram usados $1,5 \mathrm{Kg}$ de tecidos de mandioca descascada homogeneizada com água em liquidificador, passados por peneira de $150 \mu \mathrm{m}$ e de $62 \mu \mathrm{m}$, sucessivamente, para remoção parcial de amido. Os resíduos foram secos em estufa com circulação de ar a $45^{\circ} \mathrm{C}$, moídos e passados pela peneira de $150 \mu \mathrm{m}$. O preparo das amostras foi feito em duas repetições.

Dez gramas deste material foram suspensas em 200mL de água destilada e incubadas em banho-maria com água em ebulição por 20min para gelatinizar o amido. Em seguida, as amostras foram resfriadas a $50^{\circ} \mathrm{C} \mathrm{e}$ adicionadas de $50 \mathrm{~mL}$ de glucoamilase de Rhizopus sp $(0,2 \mathrm{mg} / \mathrm{mL})$ em tampão acetato $0,1 \mathrm{M}(\mathrm{pH} 4,5)$ contendo $0,01 \mathrm{M}$ de cloreto de cálcio, permanecendo no banho a $50^{\circ} \mathrm{C}$ por $30 \mathrm{~min}$ para hidrólise do amido residual. O material centrifugado foi ressuspenso e novamente tratado com glucoamilase e centrifugação até testar negativo para presença de amido com $\mathrm{I}_{2}$ em $\mathrm{KI}$ (3\% $\mathrm{I}_{2}$ em $4 \%$ de solução de KI). Os resíduos sólidos da hidrólise enzimática, constituídos por material de paredes celulares isoladas foram lavados sucessivamente com água destilada, metanol e acetona e secos à temperatura ambiente.

O material de parede celular isolado foi fracionado segundo NODA et al.[18], com 375mL de uma solução de oxalato de amônio $0,25 \%$ a $90^{\circ} \mathrm{C}$. O extrato foi dialisado e liofilizado, constituindo os polissacarídeos pécticos e o resíduo obtido foi lavado sucessivamente com água destilada, metanol e acetona. $\mathrm{O}$ resíduo insolúvel foi tratado duas vezes com uma solução de hi- dróxido de potássio 4,0M contendo $0,1 \%$ de boroidrato de sódio à temperatura ambiente por $18 \mathrm{~h}$ e os extratos alcalinos foram combinados e neutralizados com ácido acético. Em seguida foram dialisados, liofilizados e pesados, constituindo a fração hemicelulósica. O resíduo obtido foi lavado sucessivamente com água destilada, metanol e acetona e seco à temperatura ambiente, constituindo a $\alpha$-celulose.

Os açúcares das frações pectina, hemicelulose e $\alpha$ celulose foram determinados pelo método de fenol-sulfúrico, segundo DUBOIS et al.[7]. A $\alpha$-celulose sofreu uma pré-hidrólise com $\mathrm{H}_{2} \mathrm{SO}_{4} 72 \%$, segundo DEKKER \& RICHARD [6] e NODA et al. [18] antes da análise dos açúcares. A curva padrão de glicose continha de 10 a $60 \mu \mathrm{g}$ e as leituras foram efetuadas à temperatura ambiente, a 490nm em espectrofotômetro UVI Vis (Femto, modelo 482). Ácidos urônicos nas frações pectina e hemicelulose foram determinados pelo método m-hidroxidifenil, segundo AHMED \& LABAVITCH [2] e curva padrão de ácido galactuônico (10 a $60 \mu \mathrm{g} / \mathrm{mL})$.

\section{4 - Delineamento experimental}

Foi utilizado um planejamento fatorial $2 \times 2$ com duas repetições, sendo os fatores cultivar (IAPAR 19-Pioneira e Catarina Amarela) e a idade (7 e 19 meses). Análise de variância dos dados (ANOVA) foi realizada e teste de médias (Tukey) quando adequado, usando Statistica (Statsoft, Oklahoma) com nível de significância de 5\%.

\section{3 - RESULTADOS E DISCUSSÃO}

\section{1 - Composição química}

O cultivar Pioneira apresentou teores médios de matéria seca de 40,9\% e Catarina Amarela de 42,3\% e não houve diferenças entre cultivares ou épocas de plantio. Os teores de proteína bruta na mandioca descascada (Tabela 1) variaram de 1,47 a 3,42\% em base seca e foram mais altas para as amostras de raízes com menor tempo de plantio. Os lipídios apresentaram variação percentual entre 0,52 a 0,78\%, e Pioneira aos 19 meses teve a menor concentração. Os teores de cinzas encontrados variaram de 1,88 a $2,29 \%$ e foram superiores aos 7 meses para o cultivar Pioneira, mas Catarina Amarela não apresentou variação entre os tempos de plantio. Amido variou de 84,8 a $89,6 \%$ e não houve diferença quanto ao tempo de plantio para Catarina Amarela, mas para Pioneira a concentração foi superior aos 7 meses. Os teores de amido na raiz de mandioca descritos por KAJIWARA \& MAEDA [10] foram de $86,1 \%$ e por LORENZI et al. [16], de 79,06\%, entretanto estes valores podem atingir 90\% (base seca) segundo alguns autores.

Fibra bruta (FB), variou de 1,6 a 2,0\%, sendo que os cultivares com menor tempo de plantio apresentaram teores médios percentuais mais elevados, resultados que não concordam com os de KATO et al. [11], que afirmaram que quanto mais velhas as raízes, maiores eram os teores de FB modificando a textura das raízes e elevando o tempo de cocção. BUTARELO [4], não detectou dife- 
renças no teor de FB entre amostras de 12 e 25 meses de plantio, considerando as mesmas cultivares deste trabalho. O resíduo denominado $\mathrm{FB}$ contém celulose, hemicelulose e lignina, mas não representa o total destas frações segundo POMERANZ \& MELOAN [20]. Os carboidratos não amido (CNA), calculados por diferença, variaram de 2,01 a $8,88 \%$ havendo aumento com o tempo de plantio para o cultivar Pioneira. Aos 7 meses os teores percentuais destes carboidratos foram mais elevados para Catarina Amarela se comparados aos do cultivar Pioneira e não houve diferença entre as épocas de plantio para Catarina Amarela. BUTARELO [4] determinou valores crescentes de CNA com o tempo de plantio para as mesmas cultivares utilizadas neste trabalho, mas com 12 e 25 meses de plantio.

TABELA 1. Composição das raízes descascadas em g/100g de matéria seca

\begin{tabular}{lcccc}
\hline & \multicolumn{2}{c}{ IAPAR-19 Pioneira } & \multicolumn{2}{c}{ Catarina Amarela } \\
\cline { 2 - 5 } & 7 meses & 19 meses & 7 meses & 19 meses \\
\hline Proteína & $3,42 \mathrm{a} \pm 0,08$ & $1,47 \mathrm{~b} \pm 0,2$ & $3,13 \mathrm{a} \pm 0,1$ & $1,47 \mathrm{~b} \pm 0,2$ \\
Lipídios & $0,67 \mathrm{ab} \pm 0,07$ & $0,52 \mathrm{~b} \pm 0,02$ & $0,78 \mathrm{a} \pm 0,01$ & $0,69 \mathrm{a} \pm 0,01$ \\
Cinzas & $2,29 \mathrm{a} \pm 0,09$ & $1,88 \mathrm{~b} \pm 0,09$ & $2,04 \mathrm{a} \pm 0,03$ & $2,06 \mathrm{a} \pm 0,07$ \\
Amido & $89,6 \mathrm{a} \pm 0,2$ & $85,5 \mathrm{~b} \pm 0,3$ & $84,8 \mathrm{~b} \pm 1$ & $85,3 \mathrm{~b} \pm 1$ \\
Fibra bruta & $2,0 \mathrm{a} \pm 0,05$ & $1,8 \mathrm{~b} \pm 0,01$ & $2 \mathrm{a} \pm 0,01$ & $1,6 \mathrm{~b} \pm 0,01$ \\
CNA* $^{*}$ & 2 & 8,8 & 7,2 & 8,9 \\
\hline * Carboidratos não amido, calculados por diferenca
\end{tabular}

Letras distintas na linha indicam diferenças entre as médias $(p<0,05)$.

Após a tamização úmida para separação mecânica de parte do amido das raízes, como ocorre nas fecularias, o material restante foi denominado de resíduo. Na indústria, o resíduo sólido obtido após a etapa de separação do amido também é denominado massa, farelo ou bagaço e é composto pelo material fibroso da raiz contendo parte do amido que não foi possivel extrair no processamento. Este material, o resíduo industrial, é geralmente seco e vendido como farinha segundo RAUPP et al.[21]. A fração de proteína bruta nos resíduos, em base seca, variou de 0,84 a 1,35\%, Pioneira 7 meses apresentou valores superiores se comparados aos 19 meses e não houve diferença para Catarina Amarela nas duas épocas de plantio (Tabela 2). Ao desintegrar os tecidos, grânulos de amido e parte das proteínas são liberados e retirados durante o processo de filtração com água, por isso os percentuais de proteínas no resíduo foram inferiores aos encontrados nas raízes de mandioca descascada.

TABELA 2. Composição do resíduo após a separação parcial de amido por tamização em g/100g em base seca

\begin{tabular}{lcccc}
\hline & \multicolumn{2}{c}{ IAPAR-19 Pioneira } & \multicolumn{2}{c}{ Catarina Amarela } \\
\cline { 2 - 5 } & 7 meses & 19 meses & 7 meses & 19 meses \\
\hline Proteína & $1,35 \mathrm{a} \pm 0,1$ & $0,84 \mathrm{c} \pm 0,06$ & $1,3 \mathrm{ab} \pm 0,06$ & $0,92 \mathrm{bc} \pm 0,1$ \\
Lipídios & $0,79 \mathrm{a} \pm 0,05$ & $0,21 \mathrm{~b} \pm 0,03$ & $0,82 \mathrm{a} \pm 0,09$ & $0,26 \mathrm{~b} \pm 0,02$ \\
Cinzas & $1,13 \mathrm{a} \pm 0,05$ & $0,94 \mathrm{a} \pm 0,1$ & $1,02 \mathrm{a} \pm 0,05$ & $0,96 \mathrm{a} \pm 0,01$ \\
Amido & $82,3 \mathrm{~b} \pm 3,2$ & $90,2 \mathrm{a} \pm 0,8$ & $83,9 \mathrm{~b} \pm 2,6$ & $88,8 \mathrm{a} \pm 0,2$ \\
Fibra bruta & $7,4 \mathrm{a} \pm 0,2$ & $4,8 \mathrm{~b} \pm 0,4$ & $7 \mathrm{a} \pm 0,2$ & $4,9 \mathrm{~b} \pm 0,3$ \\
CNA $^{*}$ & 7 & 3 & 6 & 4,1 \\
\hline * Carboidratos não amido, calculados por diferenca &
\end{tabular}

Letras distintas na linha indicam diferenças entre as médias $(p<0,05)$.
Os lipídios no resíduo apresentaram variação de 0,21 a $0,82 \%$ e foram superiores aos 7 meses para ambos cultivares. Os teores de cinzas variaram de 0,94 a $1,13 \%$ e foram inferiores aos teores observados nas raízes de mandioca; parte tendo sido lixiviados no processo e parte extraídos junto com os grânulos de amido, mas não houve diferença entre cultivares ou épocas de plantio. LEONEL \& CEREDA [13] encontraram $1,31 \%$ de cinzas, 11,8 de fibras, $83,1 \%$ de amido, $0,47 \%$ de lipídios e 1,6\% de proteína na fração resíduo ou farelo de mandioca, após extração de amido da cultivar industrial Branca de Santa Catarina.

Os teores de amido variaram de 82,3 a 90,2\%, mas não houve diferença entre cultivares de mesma idade. As raízes mais velhas retiveram mais amido no resíduo que as mais novas, sendo possivel que a resistência das paredes celulares aumente com a idade das plantas, diminuindo a facilidade com que o processo mecânico rompe as paredes celulares para a liberar os grânulos. As amostras apresentaram teores de fibra bruta superiores aos observados nas raízes, variando de 4,78 a 7,39\% e foram superiores aos 7 meses para ambos cultivares. Segundo RAUPP et al. [21] o resíduo obtido de fecularias comerciais continha entre 69,1 e $82,9 \%$ de amido e entre 18,4 e $25,1 \%$ de fibra alimentar. A fibra alimentar compreende tanto a FB como os CNA, e a soma destas frações para as cultivares Pioneira e Catarina Amarela variaram entre 7,7 e 14,4\%, sendo os valores menores associados às raízes mais velhas.

\section{2 - Paredes celulares isoladas}

Após a hidrólise enzimática do amido, a fração denominada parede celular foi em média de $16,2 \%$ para os cultivares aos 7 meses e de $11,6 \%$ para os de 19 meses, independente do cultivar e em base seca (Tabela 3). Cultivares mais jovens apresentaram teores de parede celular mais elevados que os mais velhos, pois as raízes continuam acumulando amido enquanto estiverem no solo, diminuindo proporcionalmente o teor de paredes celulares. NODA et al. [18], empregando o mesmo procedimento para o isolamento, encontraram no resíduo sem amido da batata-doce, uma outra raiz que acumula amido, 33,4\% de parede celular. KAJIWARA \& MAEDA [10] encontraram valores médios percentuais de parede celular em mandioca de $4,5 \%$, baseado no tecido integral das raízes e empregando uma metodologia baseada em extrações sequenciais com deoxi-colato de sódio, fenol-ácido acético-água e extração de amido com 90\% dimetil-sulfoxido. SALVADOR et al. [23] encontraram $7,3 \%$ de parede celular a partir de resíduo de extração de amido de mandioca usando a metodologia de NODA et al. [18].

Após obtenção, as paredes celulares foram fracionadas em pectina, hemicelulose e $\alpha$-celulose (Tabela 3). O percentual de pectina para os dois cultivares variou de 10,8 a $15,7 \%$ do peso da inicial da parede celular, aos 7 meses a fração péctica média obtida para ambos cultivares foi $191,9 \mathrm{mg}$ e aos 19 meses $164,8 \mathrm{mg}$ e não houve diferença entre cultivares ou épocas de 
plantio. SALVADOR et al. [23] encontraram 17,8\% de pectina em material de parede celular isolada de mandioca. O precipitado obtido após o tratamento da parede celular com a solução de oxalato de amônia à quente constitui as frações $\alpha$-celulose mais hemicelulose e aos 7 meses Pioneira e Catarina Amarela apresentaram $1161,7 \mathrm{mg}$ e $1097,9 \mathrm{mg}$ de precipitado, respectivamente enquanto que aos 19 meses Pioneira apresentou $863,6 \mathrm{mg}$ de precipitado e Catarina Amarela 838,5mg.

TABELA 3. Fracionamento do material das paredes celulares em $\mathrm{g}$ e em base úmida

\begin{tabular}{lcccc}
\hline Constituíntes $\mathrm{g}$ & \multicolumn{2}{c}{ IAPAR-19 Pioneira } & \multicolumn{2}{c}{ Catarina Amarela } \\
\hline Pare de celular & 7 meses & 19 meses & 7 meses & 19 meses \\
\cline { 2 - 5 } (peso inicial) & $1,716 \mathrm{a} \pm 0,15$ & $1,201 \mathrm{~b} \pm 0,18$ & $1,529 \mathrm{a} \pm 0,05$ & $1,128 \mathrm{~b} \pm 0,01$ \\
Pectina & $0,219 \mathrm{a} \pm 0,1$ & $0,188 \mathrm{a} \pm 0,02$ & $0,165 \mathrm{a} \pm 0,02$ & $0,141 \mathrm{a} \pm 0,05$ \\
Hemicelulose & $0,02 \mathrm{a} \pm 0,01$ & $0,598 \mathrm{a} \pm 0,25$ & $0,041 \mathrm{a} \pm 0,03$ & $0,517 \mathrm{a} \pm 0,06$ \\
$\alpha$-Celulose & $1,209 \mathrm{a} \pm 0,14$ & $0,687 \mathrm{~b} \pm 0,11$ & $1,04 \mathrm{a} \pm 0,07$ & $0,744 \mathrm{~b} \pm 0,11$ \\
Recuperação g & 1,45 & 1,46 & 1,24 & 1,40 \\
$\%$ Recuperado & 84,2 & 121 & 81,2 & 124 \\
\hline
\end{tabular}

Letras distintas na linha indicam diferenças entre as médias $(p<0,05)$

A maior fração isolada de parede celular foi $\alpha$-celulose $(57,2$ a $70,4 \%)$, em média $1121,3 \mathrm{mg}$ para as plantas com menor tempo de plantio e $715,2 \mathrm{mg}$ para as mais velhas. Houve uma redução nos valores de $\alpha$-celulose com os tempos de plantio, concordando com os resultados obtidos por KETIKU \& OYENUGA [12] que encontraram $4,5 \%$ de celulose aos 5 meses de plantio e 3,4\% aos 9 meses de plantio, mas determinadas em tecidos de raízes e não em paredes celulares isoladas. SALVADOR et al. [23] encontraram $48,2 \%$ de celulose em parede celular isolada pela técnica de NODA et al. [18].

Os percentuais de hemicelulose foram de 1,2 e 2,7\% para Pioneira e Catarina Amarela aos 7 meses. A fração obtida das amostras com 19 meses de plantio não liofilizaram adequadamente e os valores foram muito mais altos devido à água presente na amostra, que tinha aspecto viscoso e elástico, diferente das amostras de hemicelulose aos 7 meses e das frações pécticas que após a liofilização estavam em pó. Provavelmente havia alguma diferença na composição da hemicelulose das raízes mais velhas que dificultou a sublimação da água durante a liofilização causando o colapso das amostras. KETIKU \& OYENUGA [12] encontraram em média $1 \%$ de hemicelulose em mandiocas colhidas entre o quinto e o nono mês após o plantio, enquanto SALVADOR et al.[23] encontraram 22,2\%. CARVALHO, CHAGAS \& COSTA [5] determinaram em média 0,28\% de pectina, $1,9 \%$ de celulose e $3,7 \%$ de hemicelulose por $100 \mathrm{~g}$ de tecido de mandioca para três cultivares em plantas com 18 meses de plantio, mas baseado em tecido integral e não em paredes celulares isoladas.

A recuperação da fração de parede celular foi de 81,2 e de $84,2 \%$ para Catarina Amarela e IAPAR-19 Pioneira aos 7 meses (Tabela 2) comparável a 88,2\% de recuperação descrito por SALVADOR et al. [23]. Valores acima de $100 \%$ foram observados nas amostras de 19 meses de plantio pois, a fração hemicelulose apresentou pro- blemas de secagem durante a liofilização. Nas amostras mais jovens houve perda de material devido as dificuldades inerentes ao método, justificando valores de recuperação inferiores a $100 \%$.

\section{3 - Determinação de açúcares e ácidos urônicos}

Os percentuais de açúcares para a fração péctica variaram de 35,7 a $47,5 \%$ e foram superiores para as amostras com maior tempo de plantio (Tabela 4), e raízes de mesma idade não apresentaram diferenças. SALVADOR et al. [23] encontraram 34,9\% de equivalentes em glicose na fração péctica isolada de paredes celulares. $\mathrm{Na}$ fração hemicelulose, equivalentes em açúcares variaram de 17,0 a $36,2 \%$ e não houve diferenças entre cultivares ou tempos de plantio pois os desvios padrões das determinações foram altos, principalmente devido ao problema de secagem das amostras. Os açúcares da fração $\alpha$-celulose variaram de 53,4 a 71,4\% e não diferiram entre as épocas de plantio ou cultivares, mas SALVADOR et al. [23] encontraram 37,7\%. Teoricamente este percentual é baixo, mas poderia ser justificado em parte, pelas dificuldades inerentes ao método de extração e à análise propriamente dita, pois a $\alpha$-celulose sofre pré-hidrólise seguida de hidrólise para liberação quantitativa de glicose.

TABELA 4. Percentagem de açúcares calculados como glicose e de ácidos urônicos, como galacturônico nas frações de paredes celulares em base úmida.

\begin{tabular}{|c|c|c|c|c|}
\hline \multirow[t]{2}{*}{ Constituinte } & \multicolumn{2}{|c|}{ IAPAR-19 Pioneira } & \multicolumn{2}{|c|}{ Catarina Amarela } \\
\hline & 7 meses & 19 meses & 7 meses & 19 meses \\
\hline \multicolumn{5}{|c|}{ Açúcares } \\
\hline Pectina & $40,4 b \pm 0,6$ & $45,9 a \pm 0,2$ & $35,7 b \pm 2,2$ & $47,5 a \pm 1,8$ \\
\hline Hemicelulose & $17,0 \mathrm{a} \pm 4,4$ & $29,7 a \pm 14$ & $24,3 a \pm 14$ & $36,2 a \pm 12$ \\
\hline$\alpha$-Celulose & $68,5 a \pm 5,4$ & $53,3 a \pm 4,9$ & $71,4 a \pm 1,8$ & $53,8 a \pm 7,2$ \\
\hline \multicolumn{5}{|c|}{ Ácidos urônicos } \\
\hline Pectina & $41,3 b \pm 0,1$ & $31,0 \mathrm{~d} \pm 0,1$ & $43,1 a \pm 0,1$ & $40,2 c \pm 0,1$ \\
\hline Hemicelulose & $13,2 a \pm 1,8$ & $1,5 a \pm 0,8$ & $21,4 a \pm 3,2$ & $1,9 a \pm 1,4$ \\
\hline
\end{tabular}

As percentagens de equivalentes a ácidos urônicos da fração pectina variaram de 31,1 a $43,1 \%$ e houve diferenças entre cultivares e datas de plantio (Tabela 4). As raízes mais jovens apresentaram valores superiores de ácidos urônicos e a concentração em Catarina Amarela foi superior a da cultivar Pioneira. Na fração hemicelulose em amostras de 7 meses $13,2 \%$ para Pioneira e $21,4 \%$ para Catarina Amarela e os valores para amostras de 19 meses de 1,49 e 1,93\%, estão comprometidos pelo problema de secagem. Nenhum dos outros autores [5, 12, 23] apresentaram desvios padrões das quantificações de diferentes componentes das paredes celulares ou de determinações químicas de açúcares e ácidos urônicos em frações isoladas [23].

\section{4 - CONCLUSÕES}

Raízes com menor tempo de plantio tinham mais proteína e fibra bruta que as de maior tempo de plantio. No material de paredes celulares isolado e fracionado, 
celulose constituiu a maior fração, seguido por pectina e hemicelulose. A fração pectina diferiu em composição tanto em açúcares calculados como glicose, que foi em média superior no material isolado de amostras com maior tempo de plantio, quanto em concentração de ácidos urônicos, que foi diferente tanto para raízes de idades diferentes como entre os cultivares.

\section{5 - REFERÊNCIAS BIBLIOGRÁFICAS}

[1] AMERICAN ASSOCIATION OF CEREAL CHEMISTS AACC. Approved Methods. St. Paul: AACC, 1995.

[2] AHMED, A.R, LABAVITCH, J. M. A simplified method for accurate determination of cell-wall uronide content. J. Food Bioch. v. 1, p. 361-365, 1976.

[3] ASSOCIATION OF OFFICIAL ANALYTICAL CHEMISTS AOAC. Official Methods of Analysis. 14th ed. Arlington: AOAC, 1984.

[4] BUTARELO, S. S. Cinética da cocção de mandioca: gelatinização do amido. Dissertação de Mestrado. 1999, 85p. Departamento de Tecnologia de Alimentos e Medicamentos, Universidade Estadual de Londrina, Brasil. $85 \mathrm{p}$.

[5] Carvalho, V. D., Chagas, S. J. R., Costa, A. C. Alterações em alguns components estruturais das raízes durante o armazenamento pós-colheita de três cultivares de mandioca. Rev. Bras. Mandioca, v. 7, n. 2, p.73-77, 1988.

[6] DEKKER, R. F. H., RICHARD, G. N. Determination of pectic substances in plant material. J. Sci. Food Agric., v. 23, p. 475-483, 1972.

[7] DUbOIS, M., GILlES, K. A., HAMILTON, J. K., REBERS, P. A., SMITH, F. Colorimetric method for determination of sugar and related substances. Anal. Chem., v.28, p. 350-362, 1956.

[8] EGGLeston, G., ASIEDU, R. Effects of boiling on the texture of cassava clones: a comparison of compressive strength, intercellular adhesion and physicochemical composition of the tuberous roots. Trop. Sci., v. 34, p. 259-273, 1994.

[9] INSTITUTO ADOLFO LUTZ - IAL Normas Analíticas. 3a ed. São Paulo: 1985.

[10] KAJIWARA, S., MAEDA, H. The monossaccharide composition of cell wall material in cassava tuber (Manihot utilissima). Agric. Biol. Chem., v. 47, n. 10, p. 2335-2340, 1983.

[11] KATO, M. S. A., CARVAlHO, V. D., CORRÊIA, H., PINTO, J. E. B. P. Efeito da poda na deterioração fisiológica e na qualidade de raízes de mandioca. Ciên. Prát., v. 11, n. 1, p. 75-84, 1987.

[12] Ketiku, A. O., OYenugA, V. A. Changes in carbohydrate constituents of cassava root tuber (Manihoc utilissima Pohl) during growth. J. Sci. Fd Agric., v.23, p. 1451-1456, 1972.
[13] LEONEL, M., CEREDA, M. P. Extração da fécula retida no resíduo fibroso do processo de produção de fécula de mandioca. Ciênc. Tecnol. Aliment., v. 20,n. 1, p. 122-127, 2000.

[14] LOH, J., BREENE, W. M. The thermal fracturability loss of edible plant tissue. J. Text. Studies, v. 12, p. 457- 471, 1981.

[15] LORENZI, J. O. Variação na qualidade culinária das raízes de mandioca. Bragantia, v. 53 , n. 2, p. 237 245, 1994.

[16] LORENZI, J. O., VAlle, T. L., MONTEIRO, D. A., PERESSIN, V. A., KANTHACK, R. A. D. Variedades de mandioca para o Estado de São Paulo. Boletim técnico $\mathrm{n}^{\circ}$ 2, Instituto Agronômico, 1996.

[17] LIU, K. Cellular, biological, and physicochemical basis for the hard to cook defect in legume seeds. Crit. Rev. Food Sci. Nutrit., v. 35, n.4, p. 263-298, 1995.

[18] NODA, T., TAKAHATA, K., NAGATA, T., SHIBUYA, N. Chemical composition of cell wall material from sweet potato starch residue. Starch/Stärke, v.35, n. 6, p. 232-236, 1994.

[19] PEREIRA, A.S., LOREnZI, J. O., VALLE, T. L. Avaliação do tempo de cozimento e padrão de massa cozida em mandiocas de mesa. Rev. Bras. Mandioca, v. 4, n. 1, p. 27-32, 1985.

[20] POMERANZ, Y., MELOAN, C. E. Food Analysis: Theory and Practice. AVI, Books, p. 563-570. Westport: 1971.

[21] RAUPP, D. S., MOREIRA, S. S., BANZATTO, D. A., SGARBIERI, V. C. Composição e propriedades fisiológico-nutritivas de uma farinha rica em fibra insolúvel obtida do resíduo fibroso de fecularia de mandioca. Ciênc. Tecnol. Aliment., v. 19, n. 2, p.205-210, 1999.

[22] SAFO-KANTANKA, O., OWUSU-NIPAH, J. Cassava varietal screening for cooking quality: relationship between dry matter, starch content, mealiness and certain microscopic observations of the raw and cooked tuber. J. Sci. Food Agric., v. 60, n. 1, p. 99$104,1992$.

[23] SAlvador, L. D., SUGANUMA, T., KITAHARA, K., TANOUE, H., ICHIKI, M. Monosaccharide composition of sweet potato fiber and cell wall polysaccharides from sweet potato, cassava, and potato analysed by high performance anion exchange chromatography with pulsed amperometric detection method. J. Agric. Food Chem., v. 48, p.3448-3454, 2000.

[24] WHEATLEY, C., IZQUIERDO, D. Estudio de caso: almacenamiento de yuca fresca. In CIAT, Documento de Trabajo n. 79, p. 66-99, 1991.

\section{6 - AGRADECIMENTOS}

Os autores agradecem à CAPES e ao CNPq pelas bolsas de mestrado e pesquisador. À Dra. Lílian Azevedo Miranda por fornecer a matéria-prima. 